\title{
Research on fast solid state DC breaker based on a natural current zero-crossing point
}

\author{
Wang XIANG, Yu HUA, Jinyu WEN (ه), \\ Meiqi YAO, Naihu LI
}

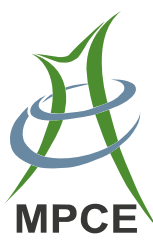

\begin{abstract}
The DC fault characteristics of voltage source converter based high voltage direct current (VSC-HVDC) systems are analyzed in this paper. The phenomenon whereby the capacitor on DC side discharges quickly during a DC fault contributes to a large short-circuit fault current. Neither traditional DC breakers nor DC switches can cut off the fault current under this condition. A fast solid state DC breaker design method is proposed in this paper. This method is based on the fault current characteristics of the inverter in multi-terminal HVDC systems (MTDC), where a fault current appears at the natural zerocrossing point near the inverter. At this point, by coordinating the AC breakers near the rectifier, the DC breaker could reliably cut off the DC fault current and protect the system. A detailed model for this fast solid state DC breaker and its operation sequence are studied, based on this design method. Simulations modeling a five-terminal meshed DC grid and a fast DC breaker were carried out with PSCAD/EMTDC using this design method. The results from the simulations confirmed the validity of the design method.
\end{abstract}

Keywords VSC-HVDC, Multi-terminal HVDC, DC short circuit fault, DC breaker

Received: 30 December 2013/ Accepted: 11 March 2014/Published online: 23 March 2014

(C) The Author(s) 2014. This article is published with open access at Springerlink.com

W. XIANG, Y. HUA, J. WEN, State Key Laboratory of Advanced Electromagnetic Engineering and Technology, Huazhong University of Science and Technology,

Wuhan 430074, China

$(\bowtie)$ e-mail: jinyu.wen@hust.edu.cn

M. YAO, N. LI, Alstom Grid China Technology Center (CTC),

Minhang District, Shanghai 201114, China

\section{Introduction}

Compared with conventional thyristor-based high voltage direct current transmission technologies [1, 2], the flexible HVDC technology (VSC-HVDC), based on voltage source converters (VSC) has many advantages. One advantage is that it highlights the independent control of the active and reactive power and has little demand for filtering and reactive power compensation devices, and the unchangeable voltage polarity when the power flow is reversed [3]. In recent years, VSC-HVDC has been quickly developed around the world. Currently, in commercial operation, VSCHVDC projects are mainly used for wind farm integrations [4], AC grid interconnections and in power supplies for isolated islands or weak power grids [5]. The large inductor in DC filters allows traditional thyristor-based HVDC systems to effectively limit the fault current when short faults occur in DC circuits [6]. However, this situation is more difficult to handle for VSC-HVDCs. Initially the voltages of the capacitors on the DC side of a VSC quickly decrease to zero. Then all the diodes which are inversely parallel with the controlled devices (such as insulated-gate bipolar transistor (IGBT) and gate turn-off (GTO) devices), begin to conduct. Owing to the lack of a reverse voltage provided by the capacitors, the AC grid will continue to feed the fault current through the uncontrolled rectifiers, which damages the voltage source converters.

Existing VSC-HVDC projects usually adopt reliable DC cables to reduce the fault rate. VSC-HVDC protection can be realized by opening the AC breakers, shutting off the entire system when a DC fault occurs (usually a permanent fault). With the development of HVDC technologies, Europe, the United States and China have successively put forward a plan for using multi-terminal HVDC systems (multi-terminal HVDC, MTDC) and DC grids [7, 8] for the integration of renewable energy. However, there is more 
than one transmission line between the converters in the multi-terminal HVDC systems and the DC grids. This may cause a large power loss and a disturbance to the power system by shutting off the entire MTDC system. Thus, it is necessary to allocate DC breakers to each transmission line to ensure the stable operation of the power system. Through the action of the DC breakers, fault cables can be cut off and isolated without shutting down the whole system. Therefore, DC breakers are essential in VSC-MTDC systems. The economical and reliable operation of VSC-MTDC systems depends on the development of the DC circuit breakers, to a great extent [9].

The absence of a natural current zero-crossing point in the DC systems causes significant differences between the requirements of the $\mathrm{AC}$ and DC breakers. DC breakers have to break short-circuit currents very quickly and need to dissipate a large amount of energy, which is then stored in the inductors in the system [10].

At present, most of the DC breakers developed in China are used in traditional HVDC projects at low and medium voltage levels. These types of DC breakers generally adopt either an active or a passive oscillating structure $[11,12]$. This structure consists of an oscillating circuit, which generates an oscillating current and produces a zero point for the current. The DC breakers are tripped as soon as the current zero point is detected. However, operation of the oscillating circuit requires a period of time that cannot satisfy the progress of the VSC-HVDC systems that discharge quickly. Moreover, without current limiting inductors, the capacities of the capacitors and inductors become enormous.

With the development of power electronic technologies, solid state circuit breakers based on fully controlled devices [13] have been well researched [14], as well as hybrid DC circuit breakers that combine solid state circuit breakers and traditional mechanical switches. However, both solid state circuit breakers and hybrid DC circuit breakers require devices that are fully controlled. Not only it is expensive, but also the operating complexity is currently far from that required for industrial applications [15].

The fault characteristic of a short circuit fault at DC side in a VSC-HVDC system is analyzed in this paper. The development of the DC circuit breakers is briefly described. Then, a fast solid state DC circuit breaker design method based on the natural current zero-crossing point at an inverter station is proposed. This is a compromising design compared with the hybrid DC breaker. The clearance of a DC fault needs to be coordinated in both the fast DC breakers stationed at the inverter state and the AC breakers stationed at the rectifier state. Finally, a multi-terminal VSC-HVDC model is established using PSCAD/EMTDC.
The simulation results verify the validity of the proposed design method.

\section{DC fault characteristic analysis in VSC-HVDC systems}

A typical two-terminal VSC-HVDC system is shown in Fig. 1. When a DC short metallic circuit fault occurred, the VSC capacitors on both ends discharged to the fault point until the DC voltage fell to zero, which caused a fault overcurrent. After the DC voltage dropped to zero, the converter was unable to continue working and transmission of the power between the rectifiers and inverters stopped. At this moment, the current in the AC system was clamped under a three-phase fault situation. After the IGBTs were blocked, the diodes turned the VSC to a non-controlled rectifier and the $\mathrm{AC}$ system continued to supply power to the fault point. The AC system or the fault cable should be cut off during the fault period to protect the whole system.

The fault period is generally divided into three stages $[16,17]$ : the capacitor discharge stage, the diode freewheel stage and the grid side current feeding stage.

\subsection{Capacitor discharge stage}

The capacitor discharge stage starts when a fault occurs and ends when the DC voltage drops to zero. This period is the natural response period of a RLC series circuit, as shown in Fig. 2.

For $R<2 \sqrt{L / C}$, the solution of the second-order natural response of the circuit is an oscillation. When a fault occurs

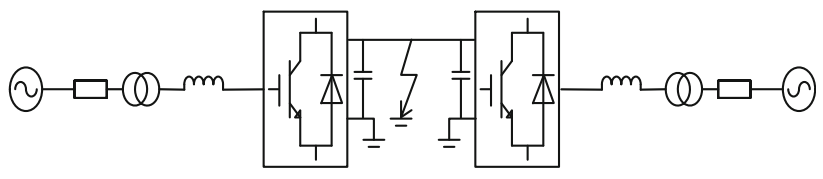

Fig. 1 Structure of a two-terminal VSC-HVDC system

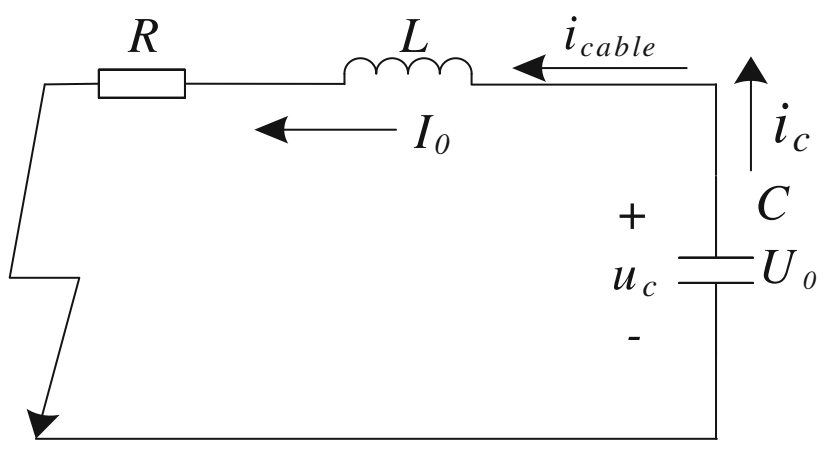

Fig. 2 Stage 1-capacitor discharge 
at $t_{0}$, under initial conditions of $u_{c}\left(t_{0}\right)=U_{0}$ and $i_{\text {cable }}\left(t_{0}\right)=I_{0}$, the natural response is:

$u_{c}=\frac{U_{0} \omega_{0}}{\omega_{d}} e^{-\alpha t} \sin \left(\omega_{d} t+\beta\right)-\frac{I_{0}}{\omega_{d} C} e^{-\alpha t} \sin \left(\omega_{d} t\right)$,

$i_{\text {cable }}=-\frac{I_{0} \omega_{0}}{\omega_{d}} e^{-\alpha t} \sin \left(\omega_{d} t-\beta\right)+\frac{U_{0}}{\omega_{d} L} e^{-\alpha t} \sin \left(\omega_{d} t\right)$,

$P_{\text {fault }}=u_{c} \cdot i_{\text {cable }}$,

where

$\alpha=\frac{R}{2 L}, \omega_{0}=\sqrt{\frac{1}{L C}}, \quad \omega_{d}=\sqrt{\omega_{0}^{2}-\alpha^{2}}, \quad \beta=\arctan \frac{\omega_{d}}{\alpha}$.

The time when the capacitor voltage drops to zero is:

$t=\frac{\pi-\theta}{\omega_{d}}, \theta=\arctan \frac{U_{0} \omega_{d}}{\alpha U_{0}-I_{0}}$.

\subsection{Diode freewheel stage}

The diode freewheel stage starts at the moment when the capacitor voltage drops to zero and ends when the capacitor starts recharging. This period is the decay process of the cable current. The circuit for this stage is shown in Fig. 3.

Assuming that the initial current of this stage is $I_{0}$, the cable current can be described as $i_{\text {cable }}=I_{0}^{\prime} e^{-(R / L) t}$. This is the most challenging period for diodes because of the high initial current.

\subsection{Grid side current feeding stage}

The grid side current feeding stage starts when the cable current drops to zero. In this stage, the VSC acts as a noncontrolled rectifier as it blocks the IGBTs. The equivalent circuit is shown in Fig. 4.

\section{The principal analysis of the DC breakers}

Currently, the research on DC circuit breakers consists of traditional DC circuit breakers, solid-state DC circuit

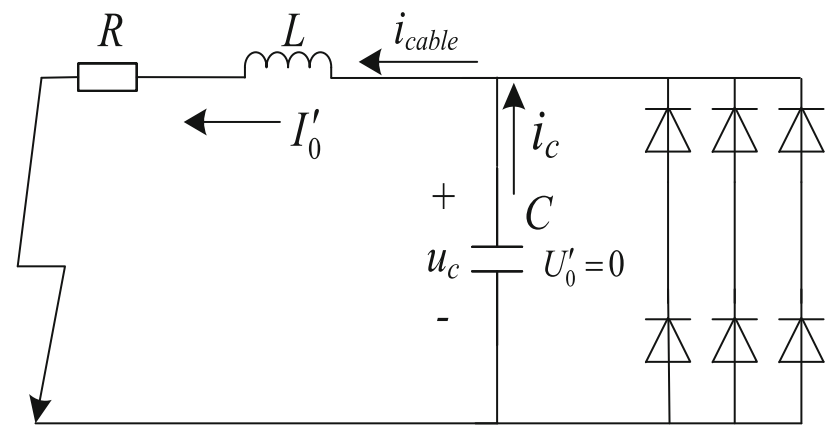

Fig. 3 The diode freewheel circuit

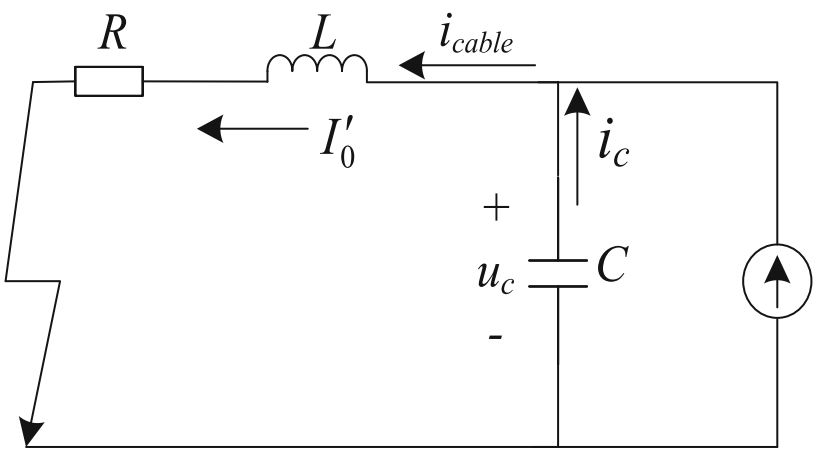

Fig. 4 Grid current feeding

breakers and hybrid DC circuit breakers. These three types of DC circuit breakers each have their own applications.

\subsection{Traditional DC breakers}

Generally, an oscillation method is applied to traditional DC breakers. Thus, oscillator circuits are used in DC circuit breakers. LC circuits are used when DC breakers need to be tripped. The current zero-crossing point is generated by an oscillating current. According to different generations of LC oscillation circuits, breakers can be classified into two types; active and passive DC circuit breakers [18], as shown in Fig. 5.

Both passive and active DC breakers are suitable for medium voltage and power level applications. For VSCHVDC systems without current limiting inductors, capacitors and inductors with a huge capacity are needed. Moreover, the action speed is much slower than the discharging speed of the capacitors on DC side.

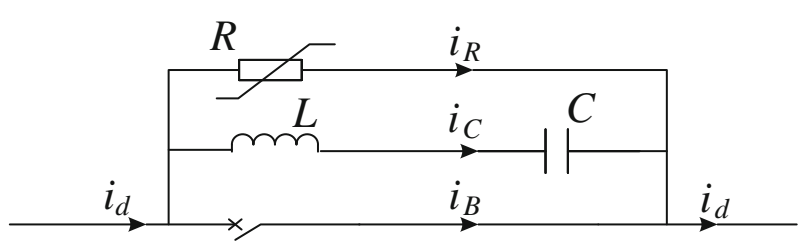

(a) Passive

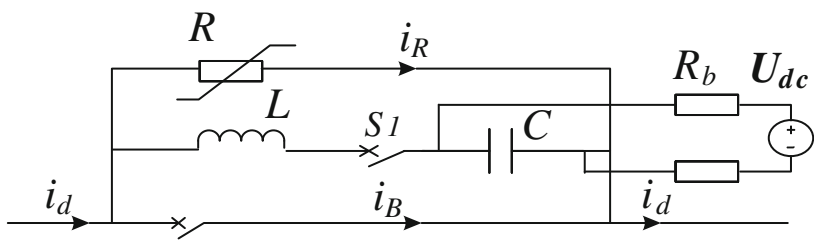

(b) Active

Fig. 5 Structures of $\mathbf{a}$ a passive and $\mathbf{b}$ an active oscillatory DC circuit breaker 


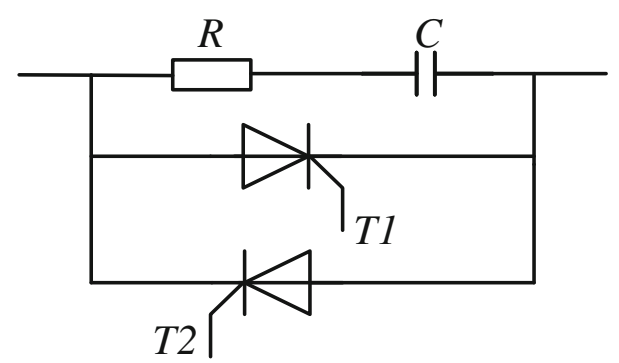

Fig. 6 Structure of a solid state DC breaker

\subsection{Solid state DC breakers}

Solid state DC breakers are composed of power electronic devices that act quickly without arcing, as shown in Fig. 6. The thermal limit of the fully controlled devices is small. To dissipate the large amount of energy, the devices should either be in series or in parallel. However, some problems still need to be solved to achieve static and dynamic stability. These include: 1) Synchronization of the problems associated with the control of each firing signal. The asynchronism of the firing signals causes asynchronous operation of the devices, which leads to an imbalance among the electronic devices, causing some of the devices to burn out. 2) Problems with balancing the voltage and current in each electronic device, caused by the dispersible switching characteristics of the devices, and a delay in the transmission time of each drive circuit may cause the imbalance in the voltage and current, which will damage the DC breaker. 3) Switching loss problems: A large number of electronic devices can cause considerable switching losses. Therefore, because of the high cost, high conduction loss, problems balancing the voltage and current, and synchronization firing control problem, DC breakers are difficult to realize.

\subsection{Hybrid DC breakers}

Hybrid circuit breakers based on a zero voltage switching principle [19] were composed of power electronic devices in parallel, which acted as a non-contact switch and a mechanical switch. The switching losses are less than that in completely solid state breakers, but the mechanical circuit breakers limit the action time. The structure is shown in Fig. 7. Meanwhile, a topology [20] that can be realized by cutting off the DC fault cables at high voltages and power levels has been proposed by ABB, as Fig. 8 shows. The DC Breaker was separated into several sections with individual arrester banks that were dimensioned for the full capability of breaking the voltage and current, whereas, auxiliary DC breakers match their lower voltage and current capabilities. After a fault is

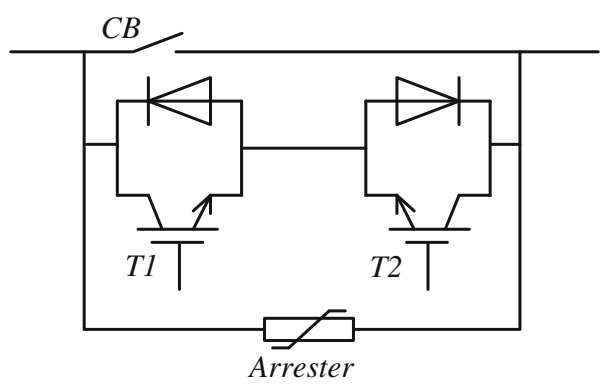

Fig. 7 Structure of a hybrid DC breaker

cleared, the disconnecting residual DC current breaker isolates the faulty cable from the DC grid to protect the arrester banks of the hybrid DC breaker from thermal overload. During normal operation, the current only flows through the bypass and the current in the main breaker is zero. When a DC fault occurs, the auxiliary DC breaker immediately commutates the current to the main DC breaker and the fast disconnector is opened. The main DC breaker cuts off the current when the mechanical switch is opened [21].

The large amount of IGBTs and arresters in DC breakers make them expensive and they are not often used for industrial and commercial applications at present.

The characteristics of the three types of DC circuit breakers are shown in Table 1.

\section{Natural current zero-crossing point analysis}

When line-to-line or line-to-ground DC faults occur in the VSC-HVDC systems, from (1), the fault current and voltage in the circuit breaker provided by the capacitors on the DC side of the circuit at the fault point are as follows:

$i_{\text {cable }}=-\frac{I_{0} \omega_{0}}{\omega_{d}} e^{-\alpha t} \sin \left(\omega_{d} t-\beta\right)+\frac{U_{0}}{\omega_{d} L} e^{-\alpha t} \sin \left(\omega_{d} t\right)$

$u_{D C B}=L_{D C B} \frac{d i_{\text {cable }}}{d t}$.

In the inverters in the VSC-HVDC systems, the DC current flows from rectifier to the inverter. The initial current value $\left(I_{0}\right)$ in (1) is negative and there must be a zero-crossing point during the discharge of the capacitor. When a resistive grounding short circuit occurs, the equivalent resistance $R$ in Fig. 2 increases and the zerocrossing point still appears. Through rapid detection of the zero-crossing point, the DC circuit breaker acts under the condition with a zero current, which reduces the breaking capacity of the circuit breaker.

Based on this method, a fast DC circuit breaker was designed, as shown in Fig. 9. 


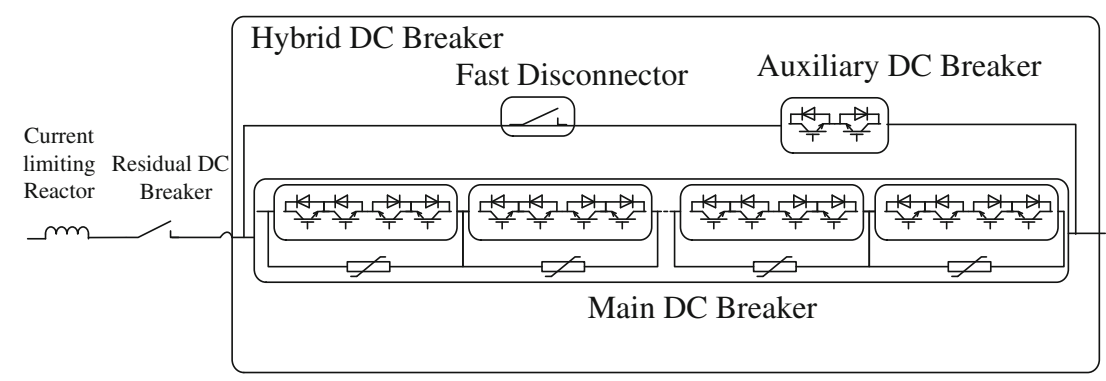

Fig. 8 Structure of a hybrid IGBT DC breaker

Table 1 Survey of the different types of DC breakers

\begin{tabular}{|c|c|c|c|}
\hline Criteria & $\begin{array}{l}\text { Traditional } \\
\text { oscillation CB } \\
\text { with arrester }\end{array}$ & Hybrid CB & $\begin{array}{l}\text { Solid State Circuit } \\
\text { Breaker without } \\
\text { auxiliary circuit }\end{array}$ \\
\hline $\begin{array}{r}\text { arc/power } \\
\text { electron }\end{array}$ & arc chamber & $\begin{array}{l}\text { power } \\
\text { electronics }\end{array}$ & power electronics \\
\hline \multirow{2}{*}{$\begin{array}{l}\text { foreseen } \\
\text { smallest } \\
\text { break time }\end{array}$} & $\begin{array}{r}40 \mathrm{~ms},(20 \mathrm{~ms}) \\
\text { for oscillation }\end{array}$ & $\sim 2 \mathrm{~ms}$ & $\sim 0.2 \mathrm{~ms}$ \\
\hline & $\begin{array}{l}+20 \mathrm{~ms} \text { arcing } \\
\text { time. }\end{array}$ & & \\
\hline $\begin{array}{l}\text { foreseen on- } \\
\text { state losses }\end{array}$ & negligible & $<5 \mathrm{~m} \Omega$ & $\begin{array}{l}\sim 100 \mathrm{~m} \Omega \\
\quad(\text { estimated })\end{array}$ \\
\hline $\begin{array}{l}\text { foreseen max } \\
\text { break current }\end{array}$ & $\begin{array}{l}\sim 4 \mathrm{kA}, \\
\quad(\text { possibly } 5 \\
\text { kA) }\end{array}$ & $\begin{array}{l}5 \mathrm{kA} \\
\text { (possibly } \\
10 \mathrm{kA})\end{array}$ & $\begin{array}{l}\text { To be further } \\
\text { investigated } \\
(\sim 6 \mathrm{kA})\end{array}$ \\
\hline scalability & yes & yes & yes \\
\hline complexity & medium & medium & high \\
\hline
\end{tabular}

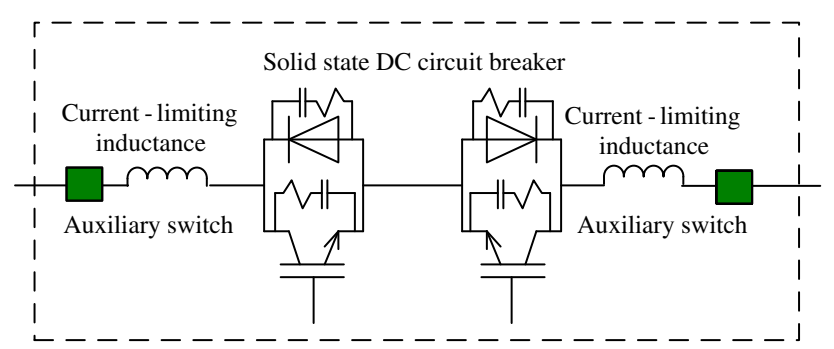

Fig. 9 Structure of a fast DC breaker

Solid state DC circuit breakers cut off the fault current at the current zero-crossing point, and then they disconnect the two auxiliary switches. Using this method, DC faults can be quickly removed. In addition, fast circuit breakers operate at the zero-crossing point, thus the short circuit capacity is small. As such, few IGBT devices are needed and additional energy consuming devices are not necessary. This has great application prospects.

The zero-crossing time is relevant to the physical parameters of fault cables, DC side capacitors and currentlimiting inductors. Moreover, the zero-crossing time is also involved with the initial line to line voltage and current before a fault occurs. However, the system voltage is controlled, thus the line current can be obtained by the transmission power. Namely, the only variables are the operation current and the fault distance, under normal circumstances. Although the zero-crossing point can be calculated with an online calculation because of the uncertainty in the fault points, operation states, and the quick action requirements of the circuit breaker, an off-line simulation setting method to obtain the current zero-crossing point time is proposed. The given VSC-HVDC model was simulated off-line and the relationship between the recorded data suddenly changed the voltage and current zero-crossing time.

When a DC fault occurs, from (6), the voltage in the current-limiting inductor suddenly changes. The peak value of the voltage is related to the length of the fault cable and the zero-crossing time. Thus, it can be realized through detecting sudden changes in the voltage to determine the fault time and the current zero-crossing time. The sequences of actions of the DC circuit breaker based on this method are as follows: 1) Initially, an offline relationship database between the sudden change in the voltage and the current zero-crossing time is established. 2) Secondly, the sudden change in the voltage in the current-limiting inductor is detected; determining whether a fault has occurred in the external cables. 3) The corresponding zero-crossing time is then obtained, according to the relationship database. 4) Then the breaking delay time through the zero-crossing time is obtained by subtracting the times consumed by the detection devices and switches. 5) The given time is then delayed, causing the circuit breaker to operate. 6) Finally, the solid state circuit breakers interrupt the current and the auxiliary switch cuts off the fault cable.

\section{Simulation validations}

5.1 Validation of the fault characteristics in a VSC-HVDC

To verify the three analysis stages outlined in section 2 , a VSC model was established using PSCAD/EMTDC. The 
cable resistance was $0.07 \Omega / \mathrm{km}$, the inductance was $0.5 \mathrm{mH} / \mathrm{km}$ [22] and the cable length was $200 \mathrm{~km}$. The VSC model was set up using the detailed IGBT models in the standard model library. The DC voltage was $800 \mathrm{kV}$ and the rated DC current was $2.3 \mathrm{kA}$. The DC cable to cable fault occurred after $1 \mathrm{~s}$. A high voltage and a high power level are a trend of future DC transmission systems with the development of power electronic technologies. Under a high voltage, it is difficult for a DC circuit breaker to cut off a DC fault current. Thus, this model adopts a DC voltage rating of $800 \mathrm{kV}$. The fault analysis method and the fast DC circuit breaker design method based on the natural current zero-crossing point can apply to different voltages.

The equivalent circuit when fault occurs is shown in Fig. 10. The capacitor discharges quickly, and as such, at this stage the main component of the cable current is the capacitor discharge current. The discharging time lasts about $6 \mathrm{~ms}$, causing the fault current to increase from 2.3 $\mathrm{kA}$ to $40 \mathrm{kA}$. The second stage begins when the capacitor voltage drops to zero. At this stage, the voltage and current of the capacitor remain zero. The attenuation time of the current attenuation in the cable is about $17 \mathrm{~ms}$. The third stage begins when the capacitor begins recharging, and then the VSC operates as an uncontrolled rectifier. The simulation waveforms for these three stages are shown in Fig. 11.

\subsection{Validation of the natural current zero-crossing point method}

To verify the correctness of the method using the natural zero-crossing point at the inverter station, a fast DC breaker model and a 5-terminal meshed DC grid model were established in PSCAD/EMTDC. The IGBTs and VSCs were all set up using this detailed model. The topology of the 5-terminal meshed DC grid is shown in Fig. 12. The parameters of each station are shown in Table 2. Under normal operation, station 2 operated as an inverter and station 3 operated as a rectifier. Thus, the fast DC breaker (BRK2) proposed in this paper was allocated at

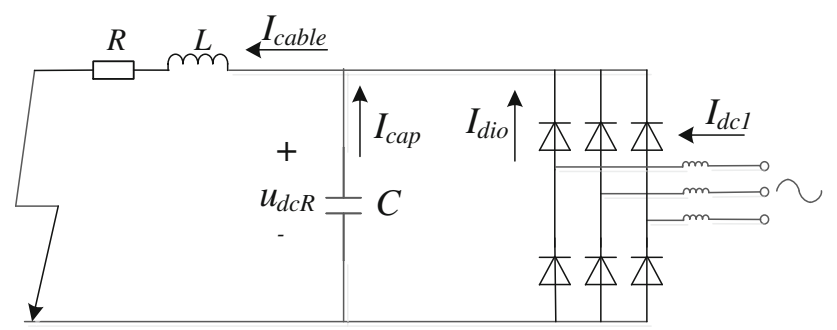

Fig. 10 Equivalent circuit of the VSC when the IGBTs are blocked station 2. Meanwhile, the hybrid DC breaker was allocated at station 3 (BRK3).

In this meshed DC grid, station 1 controls the DC voltage, while the other stations control the active and reactive power. To ground the fault a DC cable was applied on the middle of cable 23 at $1 \mathrm{~s}$. The system operated normally after $0.4 \mathrm{~s}$. The sequence of this system is as follows: 1) From 0.4 s to $1 \mathrm{~s}$, the meshed DC grid operated under normal state. 2) At $1 \mathrm{~s}$, a cable to ground DC short

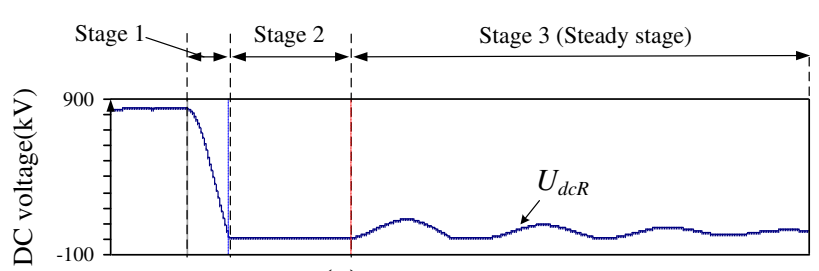

(a) DC voltage $U_{d c R} / \mathrm{kV}$

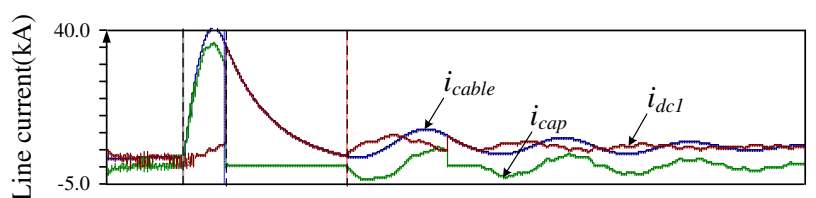

(b) Line current $i_{d c R} / \mathrm{kA}$, capacitor current $i_{c a p} / \mathrm{kA}$, feeding current by VSC $i_{d c l} / \mathrm{kA}$
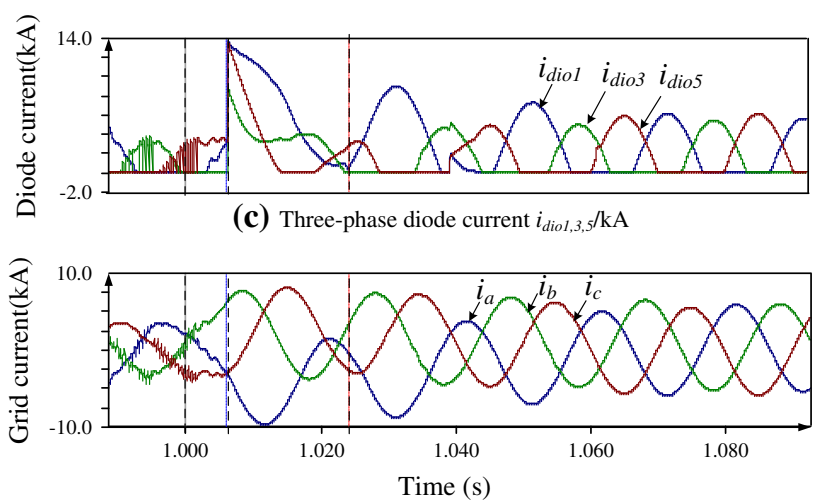

(d) Grid current $i_{a, b, c} / \mathrm{kA}$

Fig. 11 Results of a simulated DC fault in the VSC

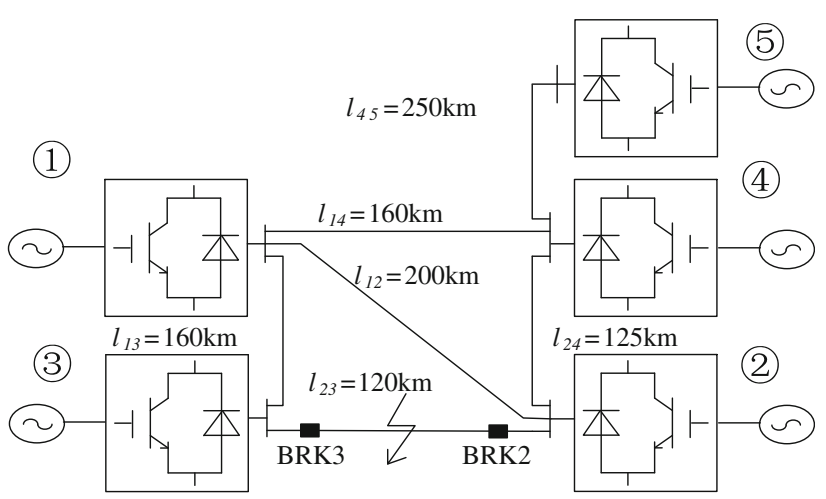

Fig. 12 Five-terminal meshed DC grid 
Table 2 Parameters for each station

\begin{tabular}{lllll}
\hline AC grid voltage/kV & $\begin{array}{l}\text { Transformer primary side/ } \\
\text { secondary side voltage } \mathrm{kV}\end{array}$ & $\begin{array}{l}\text { Transformer Impedance } \\
(\Omega)(\text { primary side })\end{array}$ & $\begin{array}{l}\text { Cable impedance/ } \\
(\Omega / \mathrm{km})\end{array}$ & $\begin{array}{l}\text { DC grid } \\
\text { voltage/kV }\end{array}$ \\
\hline 230 & $230 / 465$ & 4.197 & 0.01 & 800 \\
\hline $\begin{array}{l}\text { 1\# Station rated } \\
\text { power/MW }\end{array}$ & $\begin{array}{l}\text { 2\# Station rated } \\
\text { power/MW }\end{array}$ & $\begin{array}{l}\text { 3\# Station rated } \\
\text { power/MW }\end{array}$ & $\begin{array}{l}\text { 4\# Station rated } \\
\text { power/MW }\end{array}$ & $\begin{array}{l}5 \# \text { Station rated } \\
\text { power/MW }\end{array}$ \\
\hline 2,500 & 1,800 & 2,000 & 2,000 & 2,500 \\
\hline
\end{tabular}

circuit fault occurred in the middle of cable 23. 3) At $1.0018 \mathrm{~s}$, the fast DC breaker and hybrid DC breaker were tripped and the fault was cut off by breakers in cable 23. 4) After $1.2 \mathrm{~s}$, the DC grid system was back to its normal state of operation again.

The simulation results are shown in Figs. 13 and 14.

In Fig. 13, the natural current crossing point of the inverter fault current appeared at $1.0018 \mathrm{~s}$. The progress of the DC circuit breaker included detection, looking up the solid state circuit breaker database, and the auxiliary switching action. Therefore, the waiting time for the DC breaker to act is the setting time minus the delay times

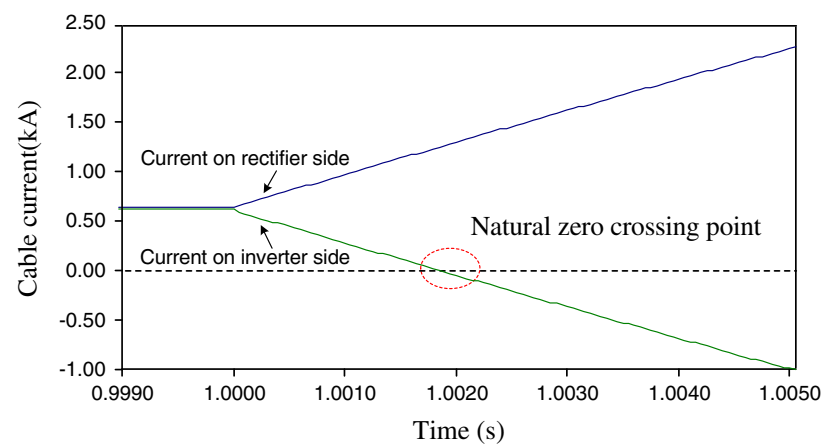

Fig. 13 Waveforms of the fault currents in cable 23

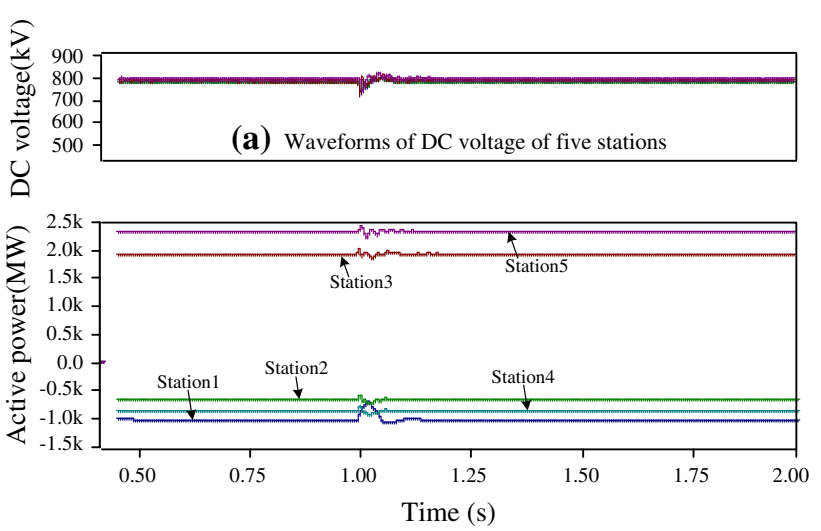

(b) Waveforms of active power of five stations

Fig. 14 Simulation results for the five stations caused by detection and looking up the database. The simulation, detection, looking-up the database and the action of the solid state circuit breaker were treated as instantaneous, namely, they were completed within one simulation step that ranged from $10 \mu$ s to $50 \mu \mathrm{s}$. In this model, the setting time was $0.0018 \mathrm{~s}$. Thus, a delay of $0.0018 \mathrm{~s}$ tripped the fast DC breaker. At the same time, the hybrid DC breaker was also tripped. After $1.2 \mathrm{~s}$, the system reached a stable state again.

The waveforms of the DC voltage and active power at each station are shown in Fig. 13 and Fig. 14, respectively. The voltage control strategy at station 1 and the power control strategy at the other stations were still effective

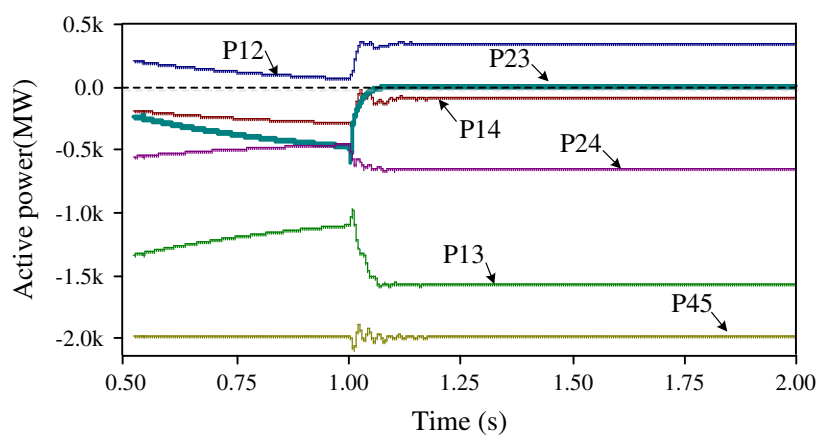

Fig. 15 Waveforms of the active power on all cables

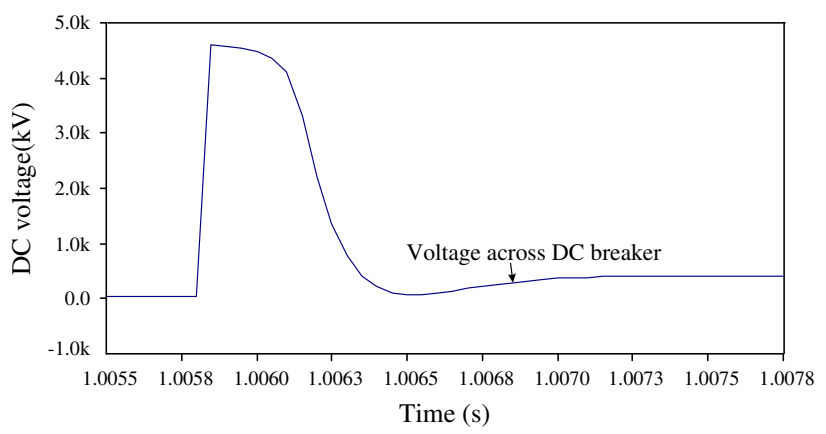

Fig. 16 Waveform of the fast DC breaker voltage 
after the DC fault had cleared. Fig. 15 presents the active power that was transmitted through cable 23, which became zero after cable 23 was cut off by the fast DC breaker and the hybrid DC breaker.

The criterion for fault detection with this design method is the circuit breaker voltage. In Fig. 16, the voltage of the DC breaker quickly increased from 0 to $4500 \mathrm{kV}$ after a DC short circuit fault had occurred. However, it had a great rise rate, which was much larger than the normal and power reverse conditions.

\section{Conclusion}

This paper introduced the working principles and current technology trends of DC breakers. The three stage characteristics of the VSC-HVDC system during a DC fault were analyzed. Further studies on the VSC-HVDC indicated that the natural current zero-crossing point appeared near the inverter when a DC short circuit occurred. A fast DC breaker design method was proposed based on this phenomenon. Detailed simulation models of the fast DC breakers and a five terminal VSC-MTDC were constructed in PSCAD/EMTDC. The simulation results proved the rationality and applicability of this fast DC breaker and its operation principle.

Acknowledgements This work is supported by National Natural Science Foundation of China under the contract 51261130484 and by State Grid Corporation of China under the contract State Grid Research 304 (2013).

Open Access This article is distributed under the terms of the Creative Commons Attribution License which permits any use, distribution, and reproduction in any medium, provided the original author(s) and the source are credited.

\section{References}

[1] Lin WX, Wen JY, Cheng SJ et al (2012) A three terminal HVDC system to bundle wind farms with conventional power plants. Proc CSEE 32(28):35-45 (in Chinese)

[2] Chen X, Lin WX, Sun HS et al (2010) LCC-MTDC technology for wind farms integration. Trans China Electrotech Soc 26(7):60-67 (in Chinese)

[3] Xu L, Andersen BR (2006) Grid connection of large offshore wind farms using HVDC. Wind Energy 9(4):371-382

[4] Flourentzou N, Agelidis VG, Demetriades GD (2009) VSCbased HVDC power transmission systems: an overview. IEEE Trans Power Electron 24(3):25-30

[5] Tang GF (2010) Voltage source converter based high voltage direct current transmission technology. China Electric Power Press, Beijing, China (in Chinese)

[6] Wasserrab A, Balzer G (2011) Calculation of short circuit currents in HVDC systems. In: Proceedings of the 46th international universities' power engineering conference (UPEC'11), Soest, Germany, 5-8 Sep 2011, 6 pp

[7] Tang GF, Luo X, Wei XG (2013) Multi terminal HVDC and DC-grid technology. Proc CSEE 33(10):8-17 (in Chinese)

[8] Gomis-Bellmunt O, Liang J, Ekanayake J et al (2011) Topologies of multiterminal HVDC-VSC transmission for large offshore wind farms. Electr Power Syst Res 81(2):271-281

[9] Frank CM (2011) HVDC circuit breakers: a review identifying future research needs. IEEE Trans Power Deliv 26(2):998-1007

[10] Pauli B, Mauthe G, Ruoss E et al (1988) Development of a high current HVDC circuit breaker with fast fault clearing capability. IEEE Trans Power Deliv 3(4):2072-2080

[11] Andersson D, Henriksson A (2001) Passive and active DC breakers in the three Gorges-Changzhou HVDC project. In: Proceedings of the international conference on power systems (CIGRE ICPS'01), Wuhan, China, 3-5 Sep 2001, pp 391-395

[12] Zhang WR, Gou RF, Zhao BN et al (2002) Study on digital simulation of transfering direct current using DC breakers. High Volt App 38(2):1-4 (in Chinese)

[13] Hu J, Wang L, Mu JG (2009) Present status of DC solid-state circuit breaker and its potential application. Power Syst Protect Control 37(19):145-150 (in Chinese)

[14] Meyer C, Kowal M, De Doncker RW (2005) Circuit breaker concepts for future high-power DC-applications. In: Conference record of the 40th Industry Applications Society annual meeting (IAS'05), vol 2, Hong Kong, China, 2-6 Oct 2005, pp 860-866

[15] Peng C, Wen JL, Wang Y et al (2012) Potential use of fault current limiter in VSC based DC transmission systems. In: Proceedings of the 2012 Asia-Pacific power and energy engineering conference (APPEEC'12), Shanghai, China, 27-29 Mar 2012, 4 pp

[16] Yang J, Fletcher JE, O'Reilly J (2012) Short-circuit and ground fault analyses and location in VSC-based DC network cables. IEEE Trans Ind Electron 59(10):3827-3837

[17] Yang J, Zheng JC, Tang GF et al (2010) Characteristics and recovery performance of VSC-HVDC DC transmission line fault. In: Proceedings of the 2010 Asia-Pacific power and energy engineering conference (APPEEC'10), Chengdu, China, 28-31 Mar 2010, 4 pp

[18] Sun SJ, Tai NL, Bo ZQ (2009) Design and simulation of DC breakers for HVDC projects. East China Electr Power 37(3):412-417 (in Chinese)

[19] Van Gelder P, Ferreira JA (2000) Zero volt switching hybrid DC circuit breakers. In: Conference record of the 35th IEEE industry Applications Society annual meeting (IAS'00), vol 5, Rome, Italy, 8-12 Oct 2000, pp 2923-2927

[20] Jovcic D, Van Hertem D, Linden K et al (2011) Feasibility of DC transmission networks. In: Proceedings of the 2nd IEEE PES international conference and exhibition on innovative smart grid technologies (ISGT Europe'11), Manchester, UK, 5-7 Dec 2011, $8 \mathrm{pp}$

[21] Häfner J, Jacobson B (2011) Proactive hybrid HVDC breakersa key innovation for reliable HVDC grids. In: Proceedings of the international symposium on integrating supergrids and microgrids, Bologna, Italy, 13-15 Sep 2011, 8 pp

[22] Yang J, O'Reilly J, Fletcher JE (2010) An overview of DC cable modelling for fault analysis of VSC-HVDC transmission systems. In: Proceedings of the 20th Australasian universities power engineering conference (AUPEC'10), Christchurch, New Zealand, 5-8 Dec 2010, 5 pp

Wang XIANG received his B.Eng. degree from Huazhong University of Science and Technology (HUST) in 2012, Wuhan, China. Now he is pursuing the Ph.D. degree in electrical power engineering at Huazhong University of Science and Technology (HUST). His main 
research interests include VSC-HVDC, modular multilevel converters and DC grids.

Yu HUA received his B.Eng. and M.Eng. degrees both from Huazhong University of Science and Technology, Wuhan, China, in 2011 and 2013, respectively. His research interest is VSC-HVDC.

Jinyu WEN received his B.Eng. and Ph.D. degrees all in electrical engineering from Huazhong University of Science and Technology (HUST), Wuhan, China, in 1992 and 1998, respectively. He was a visiting student from 1996 to 1997 and research fellow from 2002 to 2003 all at the University of Liverpool, UK, and a senior visiting researcher at the University of Texas at Arlington, USA in 2010. From 1998 to 2002 he was a director engineer in XJ Electric Co. Ltd. in China. In 2003 he joined the HUST and now is a professor at HUST. His current research interests include renewable energy integration, energy storage application, DC grid, and power system operation and control.
Meiqi YAO received the Master degree in electrical power system engineering from Northeast Dianli University, Jilin, China, in 2005. $\mathrm{He}$ is currently an Engineer for Power System Analysis at the Alstom Grid China Technology Centre, Shanghai, China.

Naihu LI received the B.Eng. and M.Sc. degrees from Southeast University in 1982 and 1985, respectively, and the Dr.-Ing. degree from Aachen University of Technology (RWTH) in Germany in 1991. He was a Professor and Dean of the Electrical Engineering School at Southeast University in China from 1992-1998. From 1999-2004, he was an R\&D Director of Rockwell Automation Shanghai Research Center. He has been the managing director of Alstom Grid China Technology Center, Shanghai, China, since 2008. His current research interests are power system automation and smart grids. 